\title{
Risk of look-a-like equipment in anesthesiology: it's not just medications
}

\author{
Christopher L. Pysyk, MD, FRCPC
}

Received: 11 August 2017/Accepted: 7 September 2017/Published online: 11 September 2017

(c) Canadian Anesthesiologists' Society 2017

The risk of safety events with look-a-like medication names, labels, and containers has been well described. Not commonly recognized, however, is the risk that look-a-like equipment may pose. Discussed below are two equipmentrelated, look-a-like threats reported to a hospital-wide, voluntary reporting system using the Patient Safety Learning System (PSLS; Datix Ltd., London, UK). In both cases, the information entered in the PSLS was reviewed by a multidisciplinary Quality and Patient Safety (QPS) Committee consisting of anesthesiologists and other perioperative allied health professionals. After discussing the events, a management plan was undertaken for each circumstance.

\section{G cutting and non-cutting spinal needles}

Following a PSLS report in which a $25 \mathrm{G}$ cutting spinal needle (Quincke type) was inadvertently opened and used when a non-cutting (pencil-point)-tip needle (Whitacre type) was intended - inspection of the spinal needle packaging for the $25 \mathrm{G}$ cutting and non-cutting needles revealed enough similarities (same colour needle hubs, same colour and size of the labeling font on packaging) to warrant review of these products on the anesthesiology equipment cart. A locally performed survey revealed that most staff anesthesiologists preferentially used the noncutting $25 \mathrm{G}$ spinal needle instead of the cutting spinal needle. Moreover, $50 \%$ of staff anesthesiologists had at one time or another inadvertently opened a cutting $25 \mathrm{G}$ spinal

C. L. Pysyk, MD, FRCPC ( $\square)$

Department of Anesthesiology and Pain Medicine, The Ottawa

Hospital, University of Ottawa, Ottawa, ON, Canada

e-mail: cpysyk@toh.ca needle when the non-cutting needle was intended. The QPS Committee thought that removal of the cutting $25 \mathrm{G}$ spinal needle from the ordering inventory was supported by the: (1) increased risk of postdural puncture headache (PDPH) with the cutting needle ${ }^{1}$; (2) potential for resource waste (unintentional opening of the cutting spinal needle, which is recognized and discarded); (3) preferential use of the non-cutting spinal needle by staff anesthesiologists.

\section{Electrical plugin for anesthesia machine}

After uneventful open reduction of an ankle fracture under general anesthesia, the portable $x$-ray machine was no longer required in the operating room (OR). In preparation to remove it from the OR, an electrical cord (thought to originate from the portable $x$-ray machine) was removed from the electrical outlet. Immediately after the power cord removal, there was a $30-\mathrm{sec}$ period of absent vital signs display on the anesthesia machine during the emergence phase. Fortunately, the functioning back-up power source on the anesthesia machine soon enabled return of vital signs display. The cause of the power outage was immediately investigated and found to be the unintentional removal of the anesthesia machine power cord. Review of the PSLS report at the QPS Committee noted that the $x$-ray and anesthesia machine electrical cords were similar in appearance (colour and size) and location on the generator-supported electrical outlet manifold. In response to these issues, the QPS Committee initiated a project to label the distal end of all anesthesia machine electrical cords with an identifying tag (Figure).

These events highlight the role played by similar appearances of equipment in our daily practice. Of note, the ability to report the event (in the PSLS) and review of 


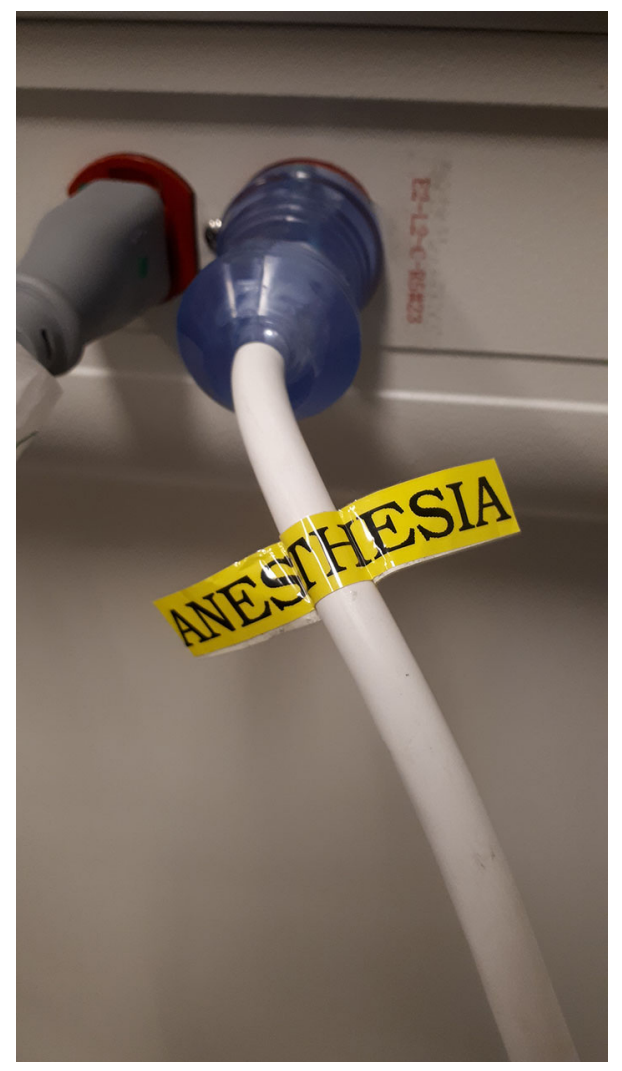

Figure Anesthesia machine electrical cord label such events (in the context of a QPS Committee) permits a local response to latent threats presented by look-a-like equipment. The actions taken relative to the events (e.g., removing the cutting spinal needle and labeling the power cords) are more effective interventions than messaging and education according to the hierarchy of effectiveness for interventions. $^{2}$

Conflicts of interest None declared.

Editorial responsibility This submission was handled by Dr. Philip M. Jones, Associate Editor, Canadian Journal of Anesthesia.

\section{References}

1. Devcic A, Sprung J, Patel S, Kettler R, Maitra-D'Cruze A. PDPH in obstetric anesthesia: comparison of 24-gauge Sprotte and 25gauge Quincke needles and effect of subarachnoid administration of fentanyl. Reg Anesth 1993; 18: 222-5.

2. Trbovich $P$, Shojania $K G$. Root-cause analysis: swatting at mosquitoes versus draining the swamp. BMJ Qual Saf 2017; 26: 350-3. 